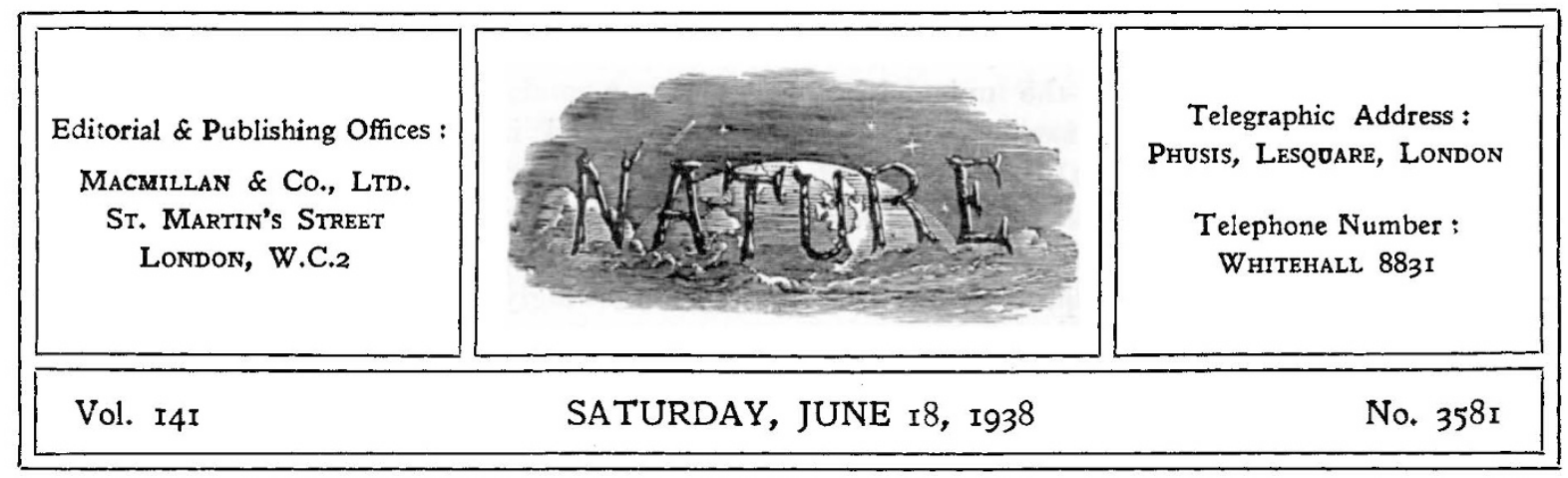

\title{
Philosophy of World Affairs
}

$\mathrm{T}$ HE impressive appeal for national unity which Mr. Eden uttered at the annual banquet of the Royal Society of St. George contained many passages which should appeal particularly to the scientific worker. Recalling the rectorial address at St. Andrews in 1934 in which General Smuts emphasized the threat to freedom and self-government even then offered by the new experiments on the Continent, and pleading for freedom not as an abstract political ideal but as a creative force inspiring youth to noble action, Mr. Eden reminded his audience that to uphold our ideals and our conception of life called for an effort and a spirit comparable with that made by the totalitarian States for their own purposes. For our faith in freedom, in toleration, in justice, the rule of law and co-operation, we should be prepared to make every contribution in our favour.

The threat to freedom of thought and speech and action grows ever greater, and the danger to-day is that in those countries which cherish liberty and democracy, the organization of defence and a common front against aggression itself tends to develop threats to freedom, which are more insidious even if closely allied to those encountered in the totalitarian State itself.

This factor, to which Walter Lippmann directed attention in his striking book "The Good Society", renders it imperative that the common effort called for from the democratic nations shall have a moral basis. This is not only the surest corrective to the insidious tendency to love "bondage with ease than strenuous liberty", but also the firmest basis for national unity.

There are no two opinions as to the supreme importance of promoting international understanding and good will, nor at the present time as to the importance of rearmament. On all sides, any policy which will lead to an appeasement of national jealousies and relieve political tension is welcomed. It is another question, however, if the expedients adopted prove obstacles in the way of that mutual trust and respect for treaty obligations in the dealings of civilized peoples with one another, upon which alone, as the Covenant of the League proclaims, relations of justice and good will can be permanently established.

The internal success of the totalitarian States has already exposed very clearly their limitations and provoked serious doubts as to how much can be hoped for from planning even in a democratic State. It is not the least service of Walter Lippmann's study of collectivism that he shows clearly its dangers even in a democratic regime. Lippmann indeed contends that planning is impossible in an true democracy, and that it depends on the authoritarian principle, which is a rejection of the wisdom of experience and the acceptance of errors which previous generations had learnt to discard.

Lippmann's contention, however unpalatable as it may be to most schools of political thought, contains too much truth in it to be lightly disregarded. Mankind unquestionably has advanced in knowledge, in the mastery of Nature, in unity, and in personal security through a progressive emancipation from the bondage of authority, monopoly and special privilege. The scientific achievements which have confronted us with some of our acutest difficulties to-day, and which by some are regarded as compelling the establishment of authority, even as they extend its power and range, have indeed become possible only as scientific inquiry was emancipated from authority. Scientific workers already have before them uncomfortable examples of the decay of scientific thought under the authoritarian regime. 
If it is by the removal of restraints, rather than by constraints, as Lippmann suggests, that men have been able to adapt themselves to the life of great societies, there is none the less no more vital problem confronting democracy than the selection of just those constraints which are essential to its security without endangering the freedom from which its vitality springs. Because to plan every detail, as in the totalitarian State, means death to individuality and progress, we are not to assume that planning has no place in a democracy. No municipality, no rural or urban community, could avoid disaster for long without some manifestation of the foresight and prevision implicit in the idea of planning. Water supply, food supply, health, transport, and even recreation, all demand a quantitative conception of the needs of a community, and an organized attempt to meet those needs.

What therefore is demanded that our planning shall have some conception of man's spiritual needs, some regard to moral values and be based on co-operation and legislation rather than command. It is the type and purpose of our planning that are vital, and the tragedy of to-day is that the effort being made to eliminate waste, to conserve national resources and to meet national needs, is so often dominated by ideas and purposes that threaten world disaster and violate the moral and spiritual needs of mankind.

Nowhere is this truer than in the international sphere, and Senor de Madariaga's recently published outline of a world commonwealth vividly attests this truth. The most urgent task, as he sees it, is to teach world opinion to appreciate that the only way out of chaos is to lay the foundation for a world community which might establish enduring peace, the inner nature of which is justice. Nationally, as internationally, the problem is fundamentally one of education. When all the resources of the totalitarian State are directed to the mass education of its citizens for nationalist purposes and individuality is warped or crushed, the chief hope of civilization lies in the education of public opinion elsewhere to the need for and possibilities of world co-operation, and in a way which may yet win the consent of the totalitarian regimes themselves.

Effective thinking on the part of the individual voter is indeed the final condition of success, and the realization that there are no longer foreign affairs but only world affairs, that it is now the world that matters and not merely those foreigners who do not belong. Even ministers of world affairs cannot solve the problems raised by those affairs unless and until they combine in a permanent system for carrying them on by constituting, either in the present League of Nations, a reformed League, or a different League, a world council for foreign affairs, which must have behind it, to be effective, a powerful élite of world citizens endowed with the necessary world patriotism to give these world statesmen their inspiration and guidance.

That is essentially the argument of Senor de Madariaga in both his books, whether as in "The World's Design" he is outlining his vision of a world commonwealth or, in "Theory and Practice in International Relations"*, discussing its practicability. Nor is his outlook unhopeful. The mere existence of a machinery of world government in the League is a symbol of unity around which much may coalesce. Senor de Madariaga points also to other factors accelerating progress-the success already achieved in international cooperation in those fields such as health and communications, where the professional interest in getting the problem solved is dominant : the slow creation of a community spirit : the moral pride which makes nations compete for the place of the most virtuous at least in international assemblies.

However threatening the situation may be, it is at least not one for despair, and it throws down a challenge not least to scientific workers. They must make their contribution to the evolution of a philosophy of world affairs in which the elements of competition, co-ordination and organization are brought into a more intelligent and co-ordinated synthesis, which preserves man's moral and intellectual freedom while ministering to his material needs. They have their professional contribution to make in special fields involved in the positive planning visualized by Senor de Madariaga, such as the establishment of a world administration for mandated territories, a world bank and a world trade commission. On them rests the responsibility for much of that research in social problems upon which such co-ordination must be based, and they can at least play a part in the education of their fellows to a vision of world affairs, the consideration of problems from the point of view of an organized and conscious mankind. The ethical declaration for the times recently issued (see

\footnotetext{
- Theory and Practice in International Relations. By Salvador de Madariaga. (The William J. Cooper Foundation Lectures 1937, Swarthmore College.) Pp. $\mathrm{v}+105$. (London: Oxford University Press, 1937.) 68. net.
} 
NAture, May 7) appears at a timely moment, and claims the allegiance and active support of all scientific workers. All that is noblest in the tradition of science urges them to make their contribution to the primary spiritual problem of creating a historical consciousness of mankind as organized dwellers of the earth and the methodical expression of it in a world State. For only as the method and energy of intelligent mankind bring order into the present chaos of man's activities can their great heritage of truth, justice, toleration and liberty be preserved for mankind.

\section{Science in the Service of Man}

Science for the Citizen:

a Self-Educator based on the Social Background of Scientific Discovery. By Lancelot Hogben. (Primers for the Age of Plenty.) Pp. 1120. (London : G. Allen and Unwin, Ltd., 1938.) 12s. 6d. net.

7 HIS is no ordinary book. Like its predecessor, "Mathematics for the Million", it is a portent of a new understanding and a new purpose in science. We have had in plenty popular expositions of scientific discoveries; we have had attempts at the analysis of the history of science ; we have had essays on its social implications; here we have all three together. They gain immensely from being presented as a unity and worked out by a single mind. In this new primer of one thousand pages, Prof. Hogben sets out to teach, to chronicle and to preach the gospel of science.

In his first main purpose, Prof. Hogben succeeds admirably. The presentation of science to the layman has rarely been at the same time so attractive and so comprehensive. Here the unity of conception of the work, the idea of science in the service of humanity, has led to an admirable balance between different branches of science, and has even succeeded in presenting science without the division into set subjects that has been the curse of its teaching throughout the last century and a half. The simplicity and directness of the explanations, and Horrabin's numerous and attractive figures, should ensure for it an even greater popularity and usefulness than had "Mathematics for the Million". The very fact that science is not presented as an explanation of the wonders of the universe but as a means to practical handling of everyday necessities should give it a wide appeal to young and active minds. In one respect, however, there is a relapse towards the older tradition of teaching. The chapters are followed by examples for working out, which are bookwork and calculations and not experiments. The audience for which Prof. Hogben is writing will surely want to do things and not only to work them out on paper.

Quite apart from its other values, "Science for the Citizen" would have to be read for the account it presents of the history of science. Here Prof. Hogben is following the modern tradition of relating the developments of science to social needs. In doing so he has given a new life and a new meaning to the records of the past and made sense of what was before merely a catalogue of mental achievements. For example, the great biological developments of the nineteenth century, the idea of evolution and the discovery of the mechanism of heredity seem no longer isolated advances but part of a renewed interest in the biological and mineral resources of the world, which were opened up by the new means of the industrial revolution, and of the need to improve stocks of animals and plants for the benefit of rapidly growing populations. Necessarily the account is abbreviated and selective, but it contains much new material and will set all scientific workers thinking of how much more needs to be done to make the history of their own fields something alive and able to point the way to future discoveries.

Prof. Hogben distinguishes clearly between three factors in the advance of science: the opportunity, the means and the motive. The opportunity lies in the social circumstances of the time, which are propitious or not to the advance of science; the means are those practical and material techniques drawn from industry or from other parts of science, without which research is impossible ; the motives determine the setting of the problem and the concentration of the scientist's attention on it.

"Whether we choose to call it pure or applied, the story of science is not something apart from the common life of mankind. What we call pure science only thrives when the contemporary social structure is capable of making full use of its teaching, furnishing it with new problems for solution and equipping it with new instruments for solving them. Without printing there would have been little demand for spectacles; without spectacles neither telescope nor microscope; without these the finite velocity of light, the annual parallax of the stars, and the micro-organisms of fermentation processes and disease would never have been known to science. Without the pendulum clock 